\title{
NO ES INCONSTITUCIONAL LA LEY QUE ESTA- BLECE EL LIMITE DE SESENTA AÑOS PARA CONCURSAR A LAS PLAZAS DE SECRETARIO, INTERVENTOR Y DEPOSITARIO DE LOS AYUN- TAMIENTOS DE MADRID Y BARCELONA
}

\author{
$340.142: 340.131 .5$
}

por

\section{Nemesio Rodríguez Moro}

Así lo viene a establecer la sentencia del Tribunal Constitucional de 3 de agosto de 1983, aunque cinco de los diez Magistrados integrantes del Tribunal formularon su voto disidente por entender que la cuestión debatida debía ser estimada, y anulada la norma objeto de litigio por estimarla contraria a la Constitución.

Es indudable que las especiales circunstancias de los Ayuntamientos de Madrid y Barcelona, con un número de habitantes en gran manera superior al resto de los Municipios españoles y con una problemática en los servicios de excepcional importancia, fueron las que llevaron al legislador a dictar leyes especiales para Madrid y Barcelona, de acuerdo con lo previsto en la Ley de 7 de noviembre de 1957. En el preámbulo de la Ley especial de Madrid, fecha 11 de julio de 1963, se consigna: «Los problemas que plantea una administración eficaz de los intereses generales de las grandes aglomeraciones urbanas constituyen hoy día una de las mayores preocupaciones de todos los Estados". Y en la Ley especial de Barcelona, fecha 23 de mayo de 1960 , se dice también en su preámbulo: "En materia de personal, se ha dedicado especial atención a la manera de designar cargos tan importantes como los de Secretario, Interventor y Depositario de Fondos de la misma. El criterio uniformista de nuestro Régimen local hace que sistemas que pueden considerarse idóneos para designar funcionarios en una aldea de 500 habitantes, resulten por completo inadecuados en la capital, 
que cuenta sus vecinos por cientos de miles. Por ello se ha creído obligado arbitrar un nuevo procedimiento para la designación de los indicados cargos, que facilita el acceso a ellos de quienes resulten más capacitados». Y así, entre las condiciones que establece el artículo 28 de la referida Ley especial, está la de que los concursantes a las vacantes de Secretario, Interventor y Depositario no podrán rebasar la edad de sesenta años. Claro que en dichas Leyes especiales se dictan normas en cuanto a organización, funcionamiento, etc., de dichos Entes municipales, pero nosotros hemos de limitar el comentario a la cuestión objeto de la sentencia del Tribunal Constitucional antes mencionada.

Como antecedentes fácticos de dicha sentencia pueden, en apretada síntesis, consignarse los siguientes:

1. Por la Dirección General de Administración Local se convocó, en diciembre de 1979, concurso para proveer la plaza de Interventor de Fondos del Ayuntamiento de Barcelona, fijando, entre otros requisitos, que los concursantes no podían rebasar la edad de sesenta años, tal y como exige el artículo 28,2 , de la Ley especial para el Municipio de Barcelona, aprobada por Decreto de 23 de mayo de 1960.

2. $\quad$ El Interventor don P. C. presentó solicitud para tomar parte en el concurso convocado, pero la Dirección General no lo admitió a concurso por exceder de los sesenta años; y como el recurso de reposición presentado fue desestimado, presentó recurso contencioso-administrativo ante la Audiencia Provincial de Barcelona (Sala 2. ${ }^{a}$ ), alegando como fundamento que la disposición legal en que se establece la limitación de los sesenta años es inconstitucional por contravenir el principio de igualdad de todos los españoles ante la ley que establece el artículo 14 de la Constitución Española.

3. Previo el trámite legal oportuno, la Sala 2. ${ }^{\circ}$ de la Audiencia Territorial de Barcelona acordó elevar el asunto al Tribunal Constitucional, por si el citado artículo $28,2, b$ ), de la Ley especial de Barcelona contraviniese la Constitución.

4. El Tribunal Constitucional acordó admitir a trámite la cuestión, y para cumplir con el procedimiento establecido al efecto dio traslado al Presidente del Congreso de los Diputados, al del Senado, al Gobierno y al Fiscal general del Estado, así como al Parlamento y al Consejo Ejecutivo de la Generalidad de Cataluña, a fin de que, si lo estimasen pertinente, se personasen e hiciesen las alegaciones que estimasen oportunas.

5. Cumplido el procedimiento, y hechas las alegaciones que se 
creyeron pertinentes, y entre las que cabe destacar la del Abogado del Estado, que encuentra de acuerdo con la Constitución y no contraria al principio constitucional de igualdad la limitación de los sesenta años objeto de controversia, sin aceptar la tesis de que el precepto cuestionado se basa en una presunción de incapacidad, sino en el deseo de obtener una mejor gestión del servicio público utilizando criterios selectivos de significación positiva; y así, bien la del Ministerio Fiscal, quien considera que el precepto dicho está en contraposición con la Constitución por cuanto se da un trato desigual a los funcionarios de una misma edad sin una justificación racional bastante para ello, el Tribunal Constitucional dictó su fallo basado en los fundamentos jurídicos que se recogen sintéticamente en los puntos siguientes:

a) El principio de la igualdad de derechos de todos los ciudadanos ante la ley implica que la norma jurídica no puede conceder privilegios ni crear situaciones de desigualdad $\mathrm{y}$, por tanto, ha de establecerse un tratamiento jurídico igual para todos los que se encuentren en las mismas situaciones. Pero claro está que en distintas situaciones, la norma puede establecer derechos diversos, aunque siempre igual para todos los que se encuentren en la misma situación. El legislador ha de establecer un trato diferencial para situaciones diferenciadas, pero todos los que se encuentren en tal situación distinta habrán de ser tratados jurídicamente igual. Y, por otra parte, el legislador no puede crear ad libitum situaciones especiales, sino que ha de tener para ello una justificación objetiva y razonable, de acuerdo con criterios y juicios de valor generalmente aceptados, debiendo estar proporcionados los medios empleados con la finalidad perseguida, aunque es lógico que el legislador tenga la suficiente libertad de movimientos para apreciar el cuándo y el modo de establecer la situación que sea procedente diferenciar.

b) La edad, dentro de los límites que la ley establece para el acceso y permanencia en la función pública, es una de las circunstancias comprendidas en los artículos 14 y 23, 2, de la Constitución Española desde la perspectiva de tratos discriminatorios, que son prohibidos como contrarios al principio básico de igualdad de todos ante la ley. Pero de aquí no cabe inferir que todos los funcionarios puedan acceder, cualquiera que sea su edad, a todos los puestos de la organización administrativa pública. Unas veces puede haber razones importantes para que el acceso a determinados puestos se limite a los que tengan cumplida una determinada edad, y otras, por el contrario, puede ser conveniente al interés público que, cumplida 
una determinada edad, no pueda accederse a ciertos y concretos puestos. Como consigna el Tribunal, "en cuanto a la edad es en sí un elemento diferenciador, y será legítima una decisión legislativa que, atendiendo a ese elemento diferenciador y a las características. del puesto de que se trate, fije objetivamente límites de edad que suponga para los que la hayan rebasado la imposibilidad de acceder a estos puestos».

c) En relación con los motivos objetivos y razonables que hayan movido al legislador para establecer esa limitación de edad para el Secretario, Interventor y Depositario para concursar a las plazas: de Madrid y Barcelona, aduce el Tribunal lo siguiente:

1. No cabe señalar como fundamento la hipotética falta de capacidad o disminución de la misma en los mayores de sesenta años para desempeñar tales cargos, pues si en verdad la edad impone ciertas limitaciones en la actividad, no puede, ciertamente, afirmarse que la edad de sesenta años lleve a una tal incapacidad o disminución de la capacidad en unas funciones que no exigen una especial capacidad física, sino meramente mental, intelectual, y en esta clase de funciones se está a esa edad en perfectas condiciones de afrontar la responsabilidad del cargo, aunque sean muchas y muy importantes las actividades en Ayuntamientos de tanta importancia. Y no sería congruente afirmar tal limitación de capacidad cuando se está reconociendo en los Secretarios, Interventores y Depositarios de dichos Ayuntamientos de sesenta años de aquellos que, acaso habiendo accedido al cargo poco antes de haber cumplido los sesenta años, van a estar desempeñándolo hasta la jubilación forzosa a los setenta años.

2. Tampoco puede aceptarse que la finalidad de tal disposición específica para los altos cargos de los Ayuntamientos de Madrid y Barcelona sea garantizar la continuidad del funcionario, pues a cualquiera se le alcanza que el nombrado puede renunciar a la plaza cuando lo crea conveniente, como puede incapacitarse para continuar desempeñándola o morir antes de llegar a la edad de jubilación forzosa. Pero lo que no cabe duda es que habrá una mayor permanencia en el cargo, en términos generales, si se nombra a funcionarios de menos de sesenta años, que si ocupan tales cargos personas de sesenta y siete o sesenta y ocho años, que normalmente, y por razón de sus otros méritos y antigüedad en la carrera, serían los que, de no haberse establecido esa limitación de los sesenta años para los dos más importantes Municipios de la Nación, habrían de obtener tales plazas en los concursos convocados al efecto. 
3. La razón más objetiva y suficientemente explicativa de tal disposición es la de procurar que a tan importantes puestos vengan los que, con los méritos exigidos en cada concurso, puedan permanecer en el mismo un tiempo razonablemente largo para conocer a fondo los problemas y poder realizar así una labor más útil y una mejor y más fructífera gestión de los intereses públicos que les están confiados.

Y termina el Tribunal Constitucional diciendo que el artículo $28,2, b$ ), de la Ley especial, "con sus diferencias cualitativas sobre el régimen común de los funcionarios de Administración local, no es discriminatorio ni contrario al principio de igualdad, porque su contenido se apoya en una situación diferenciada que recibe un tratamiento singular basado en fundamentos razonables según criterios de valor aceptados con generalidad, hallándose dicha norma creada por el legislador dentro del ámbito constitucional, ya que la rebaja de edad, que es el medio empleado, sirve adecuada y proporcionalmente al objeto que se ha querido amparar y fines a conseguir".

Para que pueda conocerse en todos sus matices el razonamiento del Tribunal Constitucional, se transcriben a continuación íntegramente los fundamentos jurídicos en que basa su sentencia, como igualmente se transcribe en su totalidad el voto disidente de los Magistrados que lo suscriben. Dicen así:

\section{Fundamentos jurídicos}

1. La norma cuya constitucionalidad se cuestiona y exige pronunciamiento del Tribunal Constitucional se encuentra contenida en el artículo 28, 2, b), del Decreto 1166/1960, de 23 de mayo, por el que se aprueba el Texto Articulado de la Ley especial para el Municipio de Barcelona - reproducida y ratificada legalmente en el artículo 72, 3, del Texto Articulado de la Ley 41/1977, de 19 de noviembre, aprobado por Decreto de 6 de octubre de 1977, de Bases del Estatuto de Régimen local-, estableciéndose en ella que la provisión de plazas de Secretario general, Interventor y Depositario de Fondos para el Ayuntamiento de dicha ciudad se efectuará mediante concurso, en el que se exigirá, entre otras condiciones mínimas, la de no rebasar la edad de sesenta años, exigencia ésta que la Sala de lo Contencioso-administrativo de la Audiencia Territorial de Barcelona estimó que podía ser contraria a los artículos 23, 2, y 14 de la Constitución Española, al vincular la posibilidad de concurso a una condición o circunstancia personal fijando la edad máxima de sesenta años.

No es, sin embargo, la totalidad de dicho precepto lo que este Tribunal debe enjuiciar, sino tan sólo el condicionamiento que pone para la provisión de las plazas de Interventor de Fondos, porque el fallo del Tribunal que plantea la cuestión sólo depende de la validez de la norma cuestionada en este extremo concreto y no en los relativos a la provisión de las plazas de Secretario general y de Depositario de Fondos, por lo que a aquel contenido 
ha de limitarse forzosamente el objeto de la sentencia, porque, como ya precisó la resolución de este Tribunal número 17/1981, de 1 de junio de 1981 (Boletín Oficial del Estado núm. 143, de 6 de junio), ésta «no es una acción concedida para impugnar de modo directo y con carácter abstracto la validez de la ley", y quedaría desvirtuada en su naturaleza si a través de ella se pidieran o se hicieran "pronunciamientos innecesarios o indiferentes para la decisión del proceso en que la cuestión se suscita", y que en el presente caso tiene como questio iuris constitucionalmente relevante la del requisito de la edad a que se somete la provisión de la plaza de Interventor de Fondos del Ayuntamiento de Barcelona, por obra del artículo 28, 2, b), del Decreto 1166/1960, de 23 de mayo, por el que se aprueba el Texto Articulado de la Ley especial para el Municipio de Barcelona, todo ello en el bien entendido que esta limitación no prejuzga la decisión que pudiera adoptarse si se suscitan otros casos relativos a los demás supuestos que quedan excluidos de afectación en el proceso presente.

2. El artículo 14 de la Constitución configura el principio de igualdad ante la ley como un derecho subjetivo de los ciudadanos, evitando los privilegios y las desigualdades discriminatorias entre aquéllos, siempre que se encuentren dentro de las propias situaciones de hecho, a las que deben corresponder un tratamiento jurídico igual, pues en tales supuestos la norma debe ser idéntica para todos, comprendiéndolos en sus disposiciones y previsiones con la misma concesión de derechos que eviten las desigualdades, pues de no actuarse legislativamente de tal manera surgiría un tratamiento diferenciado a causa de una conducta arbitraria $\mathrm{o}$, al menos, no debidamente justificada del poder público legislativo. Sólo le resulta posible al legislador, en adecuada opción legislativa, establecer para los ciudadanos un trato diferenciado cuando tenga que resolver situaciones diferenciadas fácticamente con mayor o suficiente intensidad, que requieran en su solución por su mismo contenido una decisión distinta; pero a tal fin resulta indispensable que exista una justificación objetiva y razonable, de acuerdo con criterios y juicios de valor generalmente aceptados, cuya exigencia deba aplicarse en relación con la finalidad y efectos de la medida considerada, debiendo estar presente por ello una razonable relación de proporcionalidad entre los medios empleados y la finalidad perseguida y dejando, en definitiva, al legislador con carácter general la apreciación de situaciones distintas que sea procedente diferenciar y tratar desigualmente, siempre que su acuerdo no vaya contra los derechos y libertades protegidos en los artículos 53, 1, y 9, 3, de la Constitución ni sea irrazonada, según deriva todo ello de la doctrina establecida por este Tribunal Constitucional en las sentencias de 10 de julio de 1981, 14 de julio de 1982 y 10 de noviembre de este último año, así como de las sentencias del Tribunal Europeo de Derechos $\mathbf{H u}$ manos de 23 de julio de 1968 y 27 de octubre de 1975.

3. Para analizar correctamente la constitucionalidad del precepto cuestionado es menester precisar que la prohibición de discriminación, enunciada con carácter general en el artículo 14 de la Constitución Española, y concretamente en cuanto al acceso y a la permanencia en los cargos y en las funciones públicas, en el artículo 23, 2, de la Constitución Española, responde a uno de los valores superiores que según la Constitución han de inspirar el ordenamiento jurídico español, el valor de la igualdad (art. 1., 1). El derecho a la igualdad tiene un carácter general que comprende a los servidores públicos y actúa, 
en el acceso a la función pública, y a lo largo de la duración de la relación funcionarial, de modo que los ciudadanos no deben ser discriminados para el empleo público o una vez incorporados a la función pública. La edad no es de las circunstancias enunciadas normativamente en el artículo 14, pero no ha de verse aquí una intención tipificadora cerrada que excluya cualquiera otra de las precisadas en el texto legal, pues en la fórmula del indicado precepto se alude a cualquier otra condición o circunstancia personal o social, carácter de circunstancia personal que debe predicarse de la edad, de modo que la edad dentro de los límites que la ley establece para el acceso y la permanencia en la función pública es una de las circunstancias comprendidas en el artículo 14 y en el 23, 2, desde la perspectiva excluyente de datos discriminatorios. Pero sería equivocado inferir de aquí que todo funcionario, desde el momento del acceso a la función pública y en tanto no se haya operado la extinción conectada a la edad de jubilación, tiene abiertas, cualquiera que sea su edad, las posibilidades de ocupar cualquier puesto de la organización pública, pues, por el contrario, «en cuanto la edad es en sí un elemento diferenciador, será legítima una decisión legislativa que, atendiendo a ese elemento diferenciador y a las características del puesto de que se trate, fije objetivamente límites de edad que suponga, para los que la hayan rebasado, la imposibilidad de acceder a estos puestos». La cuestión es ahora el considerar si el establecimiento de una edad máxima para el acceso al cargo de Interventor en los Municipios de régimen especial de Barcelona y Madrid está dentro de esa opción legítima, lo que ha de verse desde una doble perspectiva, pues, por un lado, se trata de un régimen especial para los indicados Municipios $\mathrm{y}$, desde otro lado, de una diferenciación dentro del Municipio entre los Interventores que han rebasado esa edad y los que se encuentran dentro del límite que permite acceder al cargo.

4. Coincidentemente, todas las alegaciones realizadas en el proceso argumentan partiendo de peculiaridades del cargo cuya provisión regula; resulta correcto este planteamiento por las razones ya indicadas y que conducen a afirmar que el fundamento objetivo y razonable de la diferencia por razón de la edad ha de buscarse en la plaza en cuyo régimen general especial de provisión la desigualdad se contiene.

Partiendo de este criterio es preciso poner de relieve que no basta para justificar como razonable la desigualdad suponer la presencia de una incapacidad personal $o$, al menos, de inferior capacidad para desempeñar dicho cargo de Interventor de Fondos a partir de la superación de los sesenta años de edad, como así lo entendió el Tribunal a quo, al basarse precisamente en la inconsistencia de esta suposición al fundamentar el planteamiento de la cuestión de inconstitucionalidad, desarrollando también el mismo criterio del Ministerio Fiscal, al alegar en favor de la declaración de inconstitucionalidad que solicita, pues ciertamente no se trata de una apreciación a priori de insuficiente capacidad personal por la edad, asistiendo a ambos la razón en este rechazo de la presunción de incapacidad como fundamento del trato desigual, porque aun cuando se admitiera que el cargo de Interventor de Fondos exige una capacidad que no se posee después de los sesenta años por el funcionario, tesis difícilmente sostenible, quedaría sin explicar siempre, como agudamente señala el Ministerio Fiscal, por qué a quienes hayan superado esa edad se les impide acceder al cargo $y$, en cambio, quienes hayan accedido al mismo antes 
de alcanzarla pueden seguir desempeñándolo después ininterrumpidamente hasta el momento de alcanzar la jubilación por edad. Ciertamente, sólo cabría afirmar que existiría una presunción de incapacidad, que, a su vez, tendría que ser examinada desde el punto de vista del principio de igualdad, si resultase que la edad de sesenta años fuera el límite para el desempeño del cargo, pero no si lo es solamente para el acceso al mismo, por lo que no es correcto argumentar, como lo hace el Abogado de la Generalidad de Cataluña, a partir del artículo 103,3 , de la Constitución, en el que se establece que la ley regulará «el acceso a la función pública de acuerdo a los principios de mérito y capacidad", precepto con el que se trata de justificar constitucionalmente la norma examinada, pero que no puede valer a este fin porque, según se desprende de las razones indicadas, no es posible razonablemente aceptar que el límite de edad enjuiciado obedezca a una aventurada presunción acerca de la capacidad general de los por él afectados.

5. La sentencia de 22 de noviembre de 1982 (núm. 68/82) de este Tribunal Constitucional, recaída en el recurso de amparo número $87 / 82$, ha establecido la doctrina de que cuando se solicita la aplicación del principio de igualdad "compete a los órganos del Estado demandados en el procedimiento constitucional la carga de ofrecer los argumentos que el diferente tratamiento legal posea", exigencia la de la carga que no puede entenderse en el sentido estricto procesal de desplazamiento o inversión del onus probandi, por no tratarse ciertamente de hechos materiales, sino como imposición dialéctica justificadora de las razones y valores que hagan posible constitucionalmente la desigualdad sin caer en la discriminación producto de la irrazonabilidad y de su consecuencia, la inconstitucionalidad.

En el caso de examen se cumplió la aportación de la argumentación justificadora de la desigualdad, a juicio del Abogado de la Generalidad de Cataluña, que alegó, junto a la fundamentación por presunción de incapacidad, que se rechazó otra más convincente, sobre la causa del límite de la edad impuesto por la norma, cual es la de asegurar la más completa actuación a través de un dilatado ejercicio de la función encomendada que mejore el rendimiento del funcionario y del servicio; y también el Abogado del Estado aportó tal argumentación sobre el régimen especial que para el Municipio de Barcelona. supone el instaurar un componente organizativo que atiende a exigencias de operatividad y eficacia de la Administración, que hacen razonable exigir una edad tope para concursar, inferior a la general de los concursos ordinarios.

6. La regla enjuiciada del artículo $28,2, b$ ), con otras, constituyen el contenido de un régimen especial y singular, previsto en nuestra legislación para la importante ciudad de Barcelona -así como para la de Madrid en otra norma posterior-, que suponen un sistema de diversidad porque excepciona el de uniformidad, que no puede ser valorado o tratado desde el principio de igualdad que proclama el artículo 14 de la Constitución, ya que, por el contrario, proporciona un dato para inferir que podrán establecerse dentro de ese régimen especial peculiaridades o diferencias en la función pública, sin que por ello, desde una comparación con el régimen común, se pueda concluir que se establece un tratamiento desigual, ya que la desigualdad $-y$ la prescripción de la desigualdad - no se produce entre regímenes municipales, al surgir como inevitable y necesario establecer el régimen especial que comporta para los cargos funcionariales, y en concreto para el Interventor de 
Fondos, el establecimiento del límite de edad de sesenta años para poder concursar a la plaza del Ayuntamiento de Barcelona, tratándose indudablemente con dicho límite de evitar que tal cargo se adjudique a funcionarios que por poseer una mayor antigüedad en la carrera, tan decisiva en la resolución de los concursos, les reste un plazo relativamente breve para la jubilación, de modo que apenas tengan tiempo suficiente para imponerse de los importantes cometidos que la ley les impone desarrollar ni conocer las peculiaridades del Ayuntamiento cuyos fondos ha de intervenir, influyendo de manera decisiva en el desempeño del servicio personal y en el que ha de prestarse públicamente en favor de los ciudadanos. Deficiencias y perjuicios que se evitan con dicha medida, que permite que al tenerse acceso al cargo a una edad alejada moderadamente de la jubilación se garantice una indispensable permanencia en el cargo, con la reserva de que si se produce el cese antes de la jubilación, el cargo queda abierto a los que cumplan aquella exigencia de edad no superior a los sesenta años.

Por otro lado, si el artículo 28, 1, de la misma Ley especial exige que los funcionarios ejerzan plenamente las misiones que tengan encomendadas según la legislación común, es evidente que el Interventor de Fondos se encuentra al frente de la asesoría y fiscalización de toda la gestión financiera y económica de un Ayuntamiento tan importante y complicado como el de Barcelona, recogido por el sistema de Carta especial, con la delicada gestión contable y presupuestaria que precisa una organización eficaz y operativa que canalice el volumen del trabajo en provecho del mayor rendimiento, haciendo necesaria no sólo una experiencia adquirida en momento de plenitud de aptitudes, sino muy especialmente que se dilate en el tiempo durante espacio apreciable, para desarrollar técnica y prácticamente la función, pudiendo determinar una singularidad en el régimen especial para acceder al cargo de Interventor.

La diferenciación no constituye un específico privilegio $\longrightarrow$ su contrario, una discriminación- por razón de la edad, sino una definición objetiva y general de las condiciones que han de reunir los Interventores que quieran acceder a los Municipios de régimen especial. La igualdad de tratamiento entre los funcionarios que integran el Cuerpo nacional que puedan concursar a la plaza de Barcelona - al igual que a la de Madrid-se produce en términos abstractos, pues todos ellos, antes de cumplir la edad de sesenta años, pueden hacerlo sin excepción si concurren todas las demás condiciones legales, por lo que poseen en este sentido y alcance igualdad de oportunidades para el posible acceso a la plaza, aunque su adjudicación se decida por el mayor mérito debido a la apreciación de otros parámetros estimativos, surgiendo después de rebasar esa edad de sesenta años para todos la misma prohibición de concursar.

7. Lo expuesto conduce a justificar que el artículo $28,2, b$ ), de la Ley especial, con sus diferencias cualitativas sobre el régimen común de funcionarios de la Administración local, no es discriminatorio ni contrario al principio de igualdad, porque su contenido se apoya en una situación diferenciada que recibe un tratamiento singular basado en fundamentos razonables según criterios de valor aceptados con generalidad, hallándose dicha norma creada por el legislador dentro del ámbito constitucional, ya que la rebaja de edad, que es el medio empleado, sirve adecuada y proporcionalmente al objeto que se ha querido amparar y fines a conseguir, sin que por lo demás resulte preciso 
que el trato desigual sea el único, ni siquiera el mejor, de los instrumentos imaginables, ya que no es función de este Tribunal Constitucional formular juicios técnicos, ni tampoco de mera oportunidad, acerca de los actos y disposiciones del poder público, por lo que en tal sentido ha de resolverse la cuestión de inconstitucionalidad planteada.

\section{Fallo}

En atención a todo lo expuesto, el Tribunal Constitucional, por la autoridad que le confiere la Constitución de la Nación española,

Ha decidido:

No haber lugar a decretar la inconstitucionalidad del artículo 28, 2, b), del Decreto $1166 / 1960$, de 23 de mayo, en cuanto exige no rebasar la edad de sesenta años para tomar parte en los concursos de promoción de la plaza de Interventor de Fondos del Ayuntamiento de Barcelona.

Publíquese en el Boletín Oficial del Estado.

Dada en Madrid a 3 de agosto de 1983.-Manuel Garcfa-Pelayo y Alonso.Jerónimo Arozamena Sierra.-Manuel Diez de Velasco Vallejo.-Gloria Begué Cantón.-Luis Dízz Picazo.-Francisco Tomás y Valiente.-Rafael GómezFerrer Morant.-Angel Escudero del Corral.-Antonio Truyol Serra.-Francisco Pera Verdaguer.-Firmados y rubricados.

Voto disidente en la cuestión de inconstitucionalidad número 44/82, que formulan los Magistrados doña Gloria Begué Cantón, don luis Dfez Picazo, don Francisco Tomás y Valiente, don Rafael Gómez-Ferrer MoRant y don Antonio TRUYOL SERRA.

El artículo 28, 2, b), del Real Decreto 1166/1960, de 23 de mayo de dicho año, por el que se aprobó el Texto Articulado de la Ley especial para el Municipio de Barcelona, estableció como requisito para participar en los concursos para la provisión de plazas de Secretarios e Interventores de dicho Ayuntamiento, el de no contar con una edad superior a sesenta años, introduciendo una desigualdad por razón de edad, en el interior del Cuerpo Nacional de Secretarios e Interventores de la Administración Local y en la legislación general sobre Administración local, donde todos los funcionarios pueden concursar mientras se encuentran en activo servicio.

La sentencia de la que disentimos considera que esta desigualdad no es discriminatoria y, por consiguiente, que no viola el artículo 14 de la Constitución porque a la norma que la establece puede encontrársele un fundamento razonable, que consiste en la evitación de la multiplicidad de concursos que en otro caso se producen cuando concursan personas próximas a la edad de jubilación.

Esta solución tropieza con dificultades. Para que una eventual desigualdad entre ciudadanos que ocupan situaciones iguales quede excluida del artículo 14 de la Constitución, no basta que la opción elegida por el legislador o la norma dictada presenten una justificación razonable. No basta justificar la ratio de la norma, porque, si así fuera, la regla de la igualdad ante la ley del artículo 14 
de la Constitución se confundiría por completo con la regla de la interdicción de la arbitrariedad del artículo noveno.

El artículo 14 de la Constitución contiene tres figuras distintas:

a) Un principio general del derecho, de suerte que cualquier excepción a él tiene que ser sometida a una «estrictas interpretación «restrictivas.

b) Un derecho subjetivo de los ciudadanos que les permite recabar de los Tribunales la tutela y protección para que la igualdad rota sea restablecida.

c) Una limitación del poder legislativo, que impide que el legislador pueda dictar normas jurídicas introduciendo desigualdades.

No se trata, por consiguiente, de justificar la razón de ser de la norma para hacer posible la desigualdad, sino de justificar la ruptura de la igualdad en sí misma, que sólo puede encontrarse en una tutela de bienes jurídicos, que estén constitucionalmente protegidos y tengan carácter superior a los que resultan sacrificados, siempre que se dé una regla de proporcionalidad entre el bien protegido y el derecho sacrificado.

La medida establecida por la disposición en cuestión no cumple los antedichos requisitos. Establece una doble desigualdad:

a) La de los Municipios de Barcelona y Madrid respecto a todos los demás de España en orden a los concursos de traslado para cubrir las plazas de Interventores y otras ahora no discutidas.

b) La de los Interventores mayores de sesenta años respecto a los de edad inferior.

Ambas desigualdades exigen una justificación suficiente, que no puede consistir tan sólo en la exposición de algún argumento en favor de las normas que las contienen, pues ello sólo serviría, como ya se ha dicho, para contrarrestar la posible acusación de arbitrariedad, vedada al legislador por el artículo 9, 3, de la Constitución. La justificación implica, como mínimo, que la disposición en cuestión sea adecuada y proporcionada con el fin que persiga, y que la norma desigualitaria lo sea con carácter de generalidad o constituya una excepción justificada, y que ese fin sea de rango constitucional equiparable a la igualdad.

Si lo que el legislador preconstitucional pretendió al establecer el artículo 28, 2, b), del Decreto 1166/1960, de 23 de mayo, fue garantizar la continuidad en el ejercicio del cargo de Interventor en los citados Municipios, tal fin no resulta protegido por la norma, pues cualquier Interventor menor de sesenta años que acceda a la plaza tras concurso, puede concursar posteriormente a cualquier otra si éste es su deseo; en relación con tal supuesto no es esgrimible el juicio de probabilidad, pues la posibilidad de que se plantee tal situación basta para poner de manifiesto la inadecuación entre fin y medio normativo.

Si a favor de la limitación de edad para acceder a tal cargo hubiera una presunción de incapacidad referida a las personas de más de sesenta años, por entender que la índole y la intensidad de la función a desempeñar son inadecuadas para quienes hayan superado aquel tope de edad, la norma es intrínsecamente incoherente, porque no impide que continúen desempeñando el cargo de Interventor quienes lo sean desde antes de cumplir sesenta años hasta que cumplan los setenta. 
Si lo que se trata es de favorecer la eficacia de la gestión, tal objetivo podría lograrse estableciendo medidas que permitieran una valoración ponderada de la edad entre los diversos méritos y circunstancias de los concursantes, para lo cual no es necesaria ni proporcionada la disposición excluyente que enjuiciamos, pues bastaría otra tendente a imponer en el concurso criterios legislativos de preferencia en favor de los concursantes menores de sesenta años.

Desde este triple punto de vista, la norma en cuestión no es ni adecuada ni proporcionada para el fin que persigue, por todo lo cual no justifica el trato desigual de que hace objeto a los Interventores menores de sesenta años que podrían concursar a las plazas de Madrid y Barcelona si no fuera por este artículo $28,2, b$ ), que al ser injustificadamente desigualatorio, resulta discriminatorio y contrario al artículo 14 de la Constitución.

Tampoco reúne la norma enjuiciada el requisito de la generalidad o, al menos, el de la excepcionalidad justificada. Por qué ha de establecerse tan drástica exclusión en Madrid y Barcelona y no en cualquier otro Municipio español es algo que, cuando menos, no resulta explícita y convincentemente razonado, pero es claro que las medidas excepcionales y restrictivas requieren una justificación expresa que no se da ni en la Ley ni en la sentencia respecto a la cual disentimos.

Por otra parte, aunque la eficacia de la Administración es un bien constitucionalmente protegido por el artículo 203, 1, tal principio es de rango inferior a la igualdad, que es no sólo un derecho individual de los españoles protegible incluso por vía de amparo (arts. 14 y 53, 2, CE), sino un principio al que está sometido el legislador (arts. 14 y 9, 1, CE), e incluso un "valor superior» del ordenamiento (art. 1, 1, CE), ante el cual deben ceder otros de rango inferior, pues es indudable que no puede buscarse la eficacia de la Administración con medidas legislativas que atenten, como ocurre con la ahora enjuiciada, contra la igualdad de los ciudadanos, aparte de que desconocen el artículo 14 de la Constitución, pues las mentadas razones de organización no son peculiares de ese Ayuntamiento y, por otra parte, no determinan la necesaria proporcionalidad entre los fines que se trata de obtener y la lesión del derecho a la igualdad que producen. Debe señalarse, además, que tampoco consiguen una duración de las personas en el cargo, pues no impiden a éstas abandonarlo o renunciar a él cuando les plazca.

A la misma conclusión se puede llegar partiendo del artículo 23 de la Constitución, pues si bien este artículo reconoce el derecho de acceso a los cargos públicos en las condiciones establecidas en la ley, se hace preciso dejar en claro que el acceso no es sólo genéricamente a la función pública, sino a cada uno de sus tramos y esferas y a cada uno de los cargos, y que la remisión que el artículo 23 hace a las condiciones establecidas por la ley no es una remisión que permita en este caso una libertad absoluta del legislador, sino que encuentra los límites genéricos de la Constitución, entre los cuales se encuentra de nuevo el establecido en el artículo 14.

Por todo ello entendemos que la cuestión ha debido ser estimada y anulada, por inconstitucional, la norma discutida.

Madrid, 4 de agosto de 1983.-Gloria Begué Cantón.-Luis Díez Picazo.Francisco Tomás y VALIENTE.-Rafael Gómez-FerRer Morant.-Antonio TRUYOL SERRA.-Firmados y rubricados. 